\title{
BelÉM, CidAde NEgRa Na AMAZônia
}

BEZERRA NETO, José Maria; LAURINDO JUNIOR, Luiz Carlos (orgs.). Escravidão urbana e abolicionismo no Grão-Pará, século XIX. Jundiaí: Paco Editorial, 2020. 364 p.

C omo salienta José Maia Bezerra Neto, um dos organizadores da coletânea, na sua contribuição inicial, "Do vazio africano à presença negra”, desconhece-se ainda hoje a importância da escravidão de origem africana na Amazônia. Essa ideia da Amazônia apenas indígena ou mestiça foi construída ao longo de mais de um século por uma historiografia brasileira que quis salientar a peculiaridade ou a situação periférica da região em relação ao resto do Brasil. A historiografia nacional sobre a Amazônia focou exclusivamente na atividade econômica do extrativismo, que usava a mão de obra indígena em oposição à agricultura escravista de plantation. Mesmo a historiografia paraense mais antiga quase não menciona a escravidão de origem africana (por exemplo, Arthur Vianna) ou apenas trata dela em estudos específicos, mas não the dando a devida importância em obras mais gerais (Arthur Cezar Ferreira Reis). As coisas começaram a mudar a partir dos trabalhos pioneiros de Napoleão Figueiredo, Anaíza Vergolino e sobretudo Vicente Salles, como destaca Bezerra Neto. Destarte, acaba surpreendendo o leitor tanto a antiguidade quanto o volume da produção historiográfica regional sobre escravidão africana no Pará, passada em revista nesse ensaio, que será de grande utilidade para qualquer estudioso do assunto, quer no Pará ou mesmo, de maneira geral, nas Américas. Apenas achei que poderia 
ter incluído autores estrangeiros, como a importante monografia sobre a cabanagem, de Mark Harris, Rebellion on the Amazon (2010), e o excelente estudo de Oscar De la Torre, The People of the River: Nature and Identity in Black Amazonia, 1835-1945 (2018).

O capítulo "Belém: escravidão e liberdade na primeira metade do século XIX”, de Bárbara de Fonseca Palha, delineia a presença dos escravos na capital da província, que representavam 35,6\% da população em 1793, proporção que aumentou para mais de $45 \%$ nas décadas de 1820 e 1830, ou seja, uma proporção de habitantes escravizados superior à do Rio de Janeiro e muitas a outras cidades do Brasil Império. A autora diz que todos seriam trabalhadores cativos, mas aqui teria sido interessante termos detalhes sobre a pirâmide etária para saber melhor se esse número resultara do tráfico transatlântico do final do período colonial, de crescimento vegetativo, ou de outro fator. Adicionando a esse grupo uma população negra e afrodescendente livre, e mais um segmento caboclo vivendo na cidade, entendemos por que viajantes estrangeiros como
Alfred Russel Wallace, Henry Walter Bates e Daniel Kidder ressaltaram tanto essa presença negra quanto a mestiçagem em Belém. Ficaram fascinados "pelas mais variadas formas de mestiçagem” (Kidder), assim como pelo exotismo dos trajes e da aparência das "mamelucas" e "pardas".

Nessa altura já se constata o uso de estereótipos, como, por exemplo, o mulato "sempre disposto" para o jogo, a música e a dança, descrito por Johann Baptist von Spix e Karl Friedrich von Martius. De que maneiras as mulheres e os homens escravizados buscavam sua liberdade? $\mathrm{O}$ texto nos revela alguns perfis retratados com bastante nitidez, como a escrava Thomazia Maria, costureira, engomadeira, lavadeira e cozinheira. Devido a suas habilidades, conseguiu juntar dinheiro e dar início a uma ação na justiça para obter sua liberdade, oferecendo a quinta parte do valor pelo qual foi avaliada, passando, em 1847, a ser considerada "libertada", numa situação de alforriada sob condição que muito lembra a coartación na ilha de Cuba. A posse de escravos em Belém, pelo visto, era tão diversificada como em outras cidades, havendo pequenos, médios e 
grandes proprietários. Mas os poucos cativos que conseguiam a alforria eram, na sua grande maioria, a julgar pelos casos examinados, trabalhadores qualificados que tinham ofício e que trabalhavam em casa ou no ganho de rua.

Em "O tempo de não trabalho dos escravos e a construção de territórios negros na cidade de Belém, 1871-1888”, Luiz Carlos Laurindo Junior toma como ponto de partida o discurso da modernidade e da valorização do trabalho livre pelas elites paraenses no final do século XIX, para então se debruçar sobre seu oposto - o tempo de lazer dos escravos urbanos. Esse grupo, mais de 10.000 pessoas em 1883, mas declinando para apenas 2.500 em 1887, constituiu um contingente desproporcional na Cadeia Pública da capital. Os escravizados eram presos pelas rondas policiais por andarem de noite na rua no seu tempo de "não trabalho", categoria usado pelo autor que argumenta ser "lazer" um conceito da sociedade industrial. O autor destaca várias atividades vistas com maus olhos pelas autoridades, desde soltar pipa (ou “empinar papagaio”), a jogos de azar ("laranjinha”, p. 120). Como em outras cidades escravistas, os batuques eram sempre objeto de preocupação das autoridades, a ponto de o código de posturas de 1880 ter uma específica sobre "bulhas e vozerias”, proibindo expressamente "fazer batuques e sambas", "tocar tambor, carimbó ou qualquer outro instrumento que perturbe o sossego durante a noite” (p. 125). Além de "algazarra”, eram visados o Entrudo e até o banho nos igarapés sem roupa, atitude sempre ressaltada pelo mundo afora como ofensiva à moralidade moderna. "Um caso à parte”, segundo o autor, era a embriaguez dos escravizados, responsável por grande proporção das prisões. A documentação vista pelo autor sugere que escravos, libertos e livres pobres faziam “parcerias” e saíam pela cidade a beber. Quando munidos de armas brancas, isso podia resultar em ferimentos e até mortes. Ao mesmo tempo, todas essas atividades, argumenta Laurindo Jr., “foram elementares no processo de constituição de territórios negros na cidade” (p. 142), destacando-se aqui as tabernas, espaço multifuncional onde se misturavam escravizados, 
forros e a população livre mais pobre. Assim, sustenta o autor, "na capital do Pará também foi forjada uma “cidade negra'” (p. 148) alternativa e arredia.

Em "Escravos de forno e fogão", Sidiana Ferreira de Macêdo e José Maia Bezerra Neto examinam o papel das cozinheiras e cozinheiros escravizados. Começando pelo caso de Cordolina (pp. 156-158), que misturou uma lata de arsênico na comida da casa grande, aprendemos que cozinhar para os senhores ou para a venda na rua representava um dos trabalhos mais relevantes desempenhado pelos escravos na cidade. Tudo indica que os cozinheiros homens eram os preferidos dos grandes estabelecimentos comerciais, como padarias e confeitarias. Entre os vendedores ambulantes de comida, além de canjica, mingau, mungunzá, caruru e vatapá, o açaí era de fundamental importância, já que consumido de maneira regular por toda a população. Como o açaí era apanhado na mata, havia aqui uma possibilidade de ganho e mesmo de fuga e subsistência.

O capítulo intitulado "Liberdade tutelada” examina um ponto pouco estudado pela historiografia até agora.
Com o Treze de Maio, os ingênuos (filhos de mães escravizadas nascidos depois da lei do Ventre Livre de 1871) em princípio também se emancipavam de seus tutores, ou seja, os senhores de suas mães. No entanto, como mostra Marcelo Ferreira Lobo, um grupo significativo de senhores tentaram, e muitas vezes conseguiram, obter a tutela dos ingênuos para continuar a poder usufruir de seus serviços gratuitamente. Emocionante é o episódio de Salustiano, carapina e ex-escravo de um desembargador, lutando para resgatar sua neta Alexandrina das garras de um desses ex-senhores, que pretendia obter tutoria sobre ela para poder "educá la”. Trata-se de um grupo significativo: ao redor de dez mil no Pará durante os anos 1880 (p. 195). Como salienta o autor: "O Treze de Maio torna os que até aquele momento eram ingênuos em 'novos órfãos' e ao mesmo tempo em 'novos escravos'” (pp. 196-197). De fato, os ingênuos representavam apenas uma parcela dos pobres tutelados pela elite, justificada pela necessidade de educação daqueles menores, geralmente com objetivos de extorsão de serviços gratuitos. Muitos outros tutelados 
eram tapuios, mamelucos ou mesmo filhos de imigrantes cearenses. No interior da província, houve casos de senhores obtendo tutelas de dezenas de menores. Por isso as famílias dos ex-escravos “elaboraram estratégias para se 'tornarem aptos' a receber a tutoria de seus parentes” (p. 225). O autor destaca a importância de laços familiares e sociais anteriores ao Treze de Maio para entender essas estratégias. Acredito que esse texto inovador abre uma trilha de pesquisa interessante para explorar as relações de trabalho no pós-abolição paraense e mesmo no Brasil.

O Fundo de Emancipação, outro desdobramento da chamada Lei do Ventre Livre de 1871, é examinado por Pedro Monteiro Neves para a província do Pará. Os recursos disponibilizados pela lei, provindos do pagamento das matrículas, entre outros, eram irrisórios para o volume dos escravos existentes. Vicente Salles já opinara que o Fundo não teve, no Pará, "outro efeito senão propagandista” (cit., p. 253). Neves salienta os "desencontros estatístico sobre as cifras” referentes ao total dos escravos alforriados por essa via na província. Interessante, porém, são as estratégias dos escravizados para tentarem ser incluídos na lista da Junta Classificadora, casando-se ou buscando residir em cidades com maior possibilidade de classificação. Os senhores, por sua vez, procuravam colocar nas listas cativos inválidos, com "problema de desobediência" ou aqueles que já possuíam pecúlio. $\mathrm{O}$ autor distingue três fases para o Fundo, 1871-1874, 1875-1884 e 1885-1888. Na primeira, apenas acumulam-se recursos; na segunda, a província recebeu cinco cotas e foram emancipados ao redor de trinta a quarenta cativos por ano; e na última fase, o Pará recebeu duas cotas, mas parece que não constam dados sobre escravos alforriados, pelo menos não constam no corpo do capítulo, nem nas tabelas que o acompanham.

O capítulo "Repensando o papel da igreja católica no processo de emancipação dos escravos em fins do século XIX, 1880-1888”, de Jerusa Barros Miranda, reexamina a tese de que a Igreja católica não teria tido participação no abolicionismo, defendido por alguns historiadores do tema. A autora discute várias obras clássicas publicadas a esse respeito no Brasil desde os tempos do Império. Na última secção do artigo, 
ela levanta a hipótese, baseada na leitura do jornal católico A Boa Nova, de que não houve uma total homogeneidade de comportamento por parte do clero católico no Pará.

O último capítulo, “Abolição, abolicionismo e a Sociedade Libertadora de Benevides, 1881-1888”, apresenta a micro-história de uma sociedade abolicionista no Pará. Como demonstra Ana Carolina Trindade Cravo, sua autora, trata-se de um caso excepcional, pois essa sociedade estava localizada numa colônia agrícola perto de Belém, constituída sobretudo por colonos cearenses de condições mais modestas. A Sociedade deu início a suas atividades seguindo o padrão na província, com cerimônias públicas em que se entregavam cartas de alforria para meia dúzia de escravos escolhidos, que eram libertados pelo dinheiro arrecadado. Aos poucos, porém, a agremiação tornou-se um exemplo perigoso para a ordem escravocrata. Alguns de seus membros acoutavam escravos fugidos, cujos serviços alugavam para lavradores da área. Uma parte desses ingressos alimentavam a caixa da Libertadora. Assim, Benevides tornou-se uma “Terra da
Liberdade" no Pará, um processo que culminou com o município sendo o primeiro na província a se declarar livre da escravidão, em 30 de março de 1884. O caso da escrava Severa, refugiada na colônia Benevides depois dessa data, contribuiu para radicalizar ainda mais o movimento abolicionista. Depois de a polícia vir à sua procura e conseguir prendê-la, um grupo de trinta escravos refugiados na área, armados de cacetes, conseguiram libertá-la da cadeia, no dia 12 de agosto de 1884 . Isso resultou em reportagens desfavoráveis sobre uma "revolta escrava" na imprensa paraense e um processo judicial contra dois membros da Sociedade Libertadora, José Ferreira Braga e Antônio Paulo dos Santos. Em conclusão, a autora equipara Benevides aos quilombos abolicionistas de outras províncias, enriquecendo assim nossa compreensão do processo emancipador no Brasil.

Em suma, este livro representa uma boa amostra de pesquisas recentes a respeito da escravidão urbana e do abolicionismo em Belém. Como sempre acontece em coletâneas, a qualidade das contribuições é desigual. Algumas contribuições 
são bastante descritivas e carecem de conclusões mais abrangentes. Em um ou outro capítulo, o uso de tabelas teria ajudado muito a sistematizar a informação, ao invés de longas descrições ou listagens de dados populacionais, por exemplo. Pessoalmente, esperava encontrar uma problematização maior da peculiaridade de Belém enquanto cidade negra no contexto do Brasil ou das Américas. Permanece, assim, o desafio para os historiadores do Pará de analisar e salientar as particularidades da escravidão na província ao compará-la com outras regiões de plantation das Américas.

Matthias Röhrig Assunção (DD

Universidade de Essex 